\section{Pupil size and drug state in a reaction time task}

JOHN L. BRADSHAW, Monash University, Victoria, Australia

Changes in pupil size were monitored during the performance of an auditory reaction-time task, under three drug conditions-normal, alcohol, and amphetamine. Under amphetamine, baseline dilations were increased, but neither the shape or amplitude of the pupillary response peak nor the obtained $R T$ were otherwise affected. With alcohol, the average pupillary baselines were no lower than normal, but the response peaks were considerably flattened and $R T$ increased. Long warning foreperiods resulted in fractionally faster performance than short.

In a previous study (Bradshaw, 1969), changes in pupillary dilation were monitored during conditions of high and low background illumination while Ss performed an auditory reaction-time (RT) task. The illumination was found to determine pupillary baseline levels but not the overall amplitude of the peak at response. Kahneman, Beatty, \& Pollack (1967) have suggested that during performance of a cognitive task, such a difference might be obtainable in the shape of the peaks, depending upon background brightnesses. They proposed that the photic-cognitive interaction is analogous to what happens with a spring balance: The pupil is spring-loaded by the light response when illumination is high, but the spring is weak or absent with a low light level. The use of drugs normally considered to influence arousal levels should affect motor performance in a RT task, as well as providing more information about changes in pupillary baseline and peaking phenomena. Three experimental conditions were therefore employed, normal, alcohol, and amphetamine. The latter was chosen as a sympathomimetic drug resembling adrenalin in its effects upon blood pressure and the reticular activating system (Cole, 1967). Alcohol was employed because of its apparent detrimental effects upon performance (Wilkinson \& Colquhoun, 1968).

\section{APPARATUS}

The photographic and recording apparatus has been described elsewhere (Bradshaw, 1968), as has the RT task and equipment (Bradshaw, 1969). Briefly, with the latter, an auditory warning signal was presented over earphones. This was followed by either a long or a short warning foreperiod of $5 \frac{1}{2} \mathrm{sec}$ or $23 / 4 \mathrm{sec}$, respectively. The response signal was of slightly different pitch. The S's performance in closing a switch was measured to the nearest $1 / 100 \mathrm{sec}$ from the onset of the response signal. A marker was put on the recording film whenever any kind of signal or response occurred. Random alternations in long and short foreperiods were employed to avoid boredom and mechanical responding. For similar reasons, instantaneous auditory feedback (a change in the frequency and continuation of the response signal) was provided as reinforcement on approximately $h$ alf the sequences, whenever the S's RT exceeded an arbitrarily set criterion. This criterion was set to the approximate mean of the S's overall RT thitherto and was varied by the E accordingly.

\section{PROCEDURE}

Under the alcohol condition, a dose equivalent to $48 \mathrm{cc}$ of alcohol in a $20 \%$ solution was consumed over a 5 -min period, $25 \mathrm{~min}$ before commencement of recording. With amphetamine, $15 \mathrm{mg}$ of amphetamine sulfate were taken $75 \mathrm{~min}$ beforehand. In all cases, testing took place at $9 \mathrm{a.m}$. on an empty stomach, with abstention from coffee, tea, tobacco, and other drugs. Six Ss were used, each successively experiencing all three experimental conditions, each under a different order. Before recording commenced, $10 \mathrm{~min}$ were spent on prior practice trials and adaptation. Each condition lasted $81 / 2 \mathrm{~min}$. A cycle of warning signal, response signal, and reinforcement signal (if applicable), with intertrial pause, lasted $15 \mathrm{sec}$, for trials with both long and short warning foreperiods. Consequently, under each condition, there were 17 trials of each foreperiod length, randomly arranged.

\section{RESULTS}

Figure 1 presents the averaged pupillary response curves for six Ss each over 17 trials, at the filmed intervals of approximately 2.7 frames $/ \mathrm{sec}$. Three conditions are shown, normal and amphetamine together, and alcohol. The responses to short and long warning foreperiods are in each case given separately. Frame 1 corresponds to the onset of the warning signal. The usual pupillary peak at response is evident. The pairs of pupillary baselines under
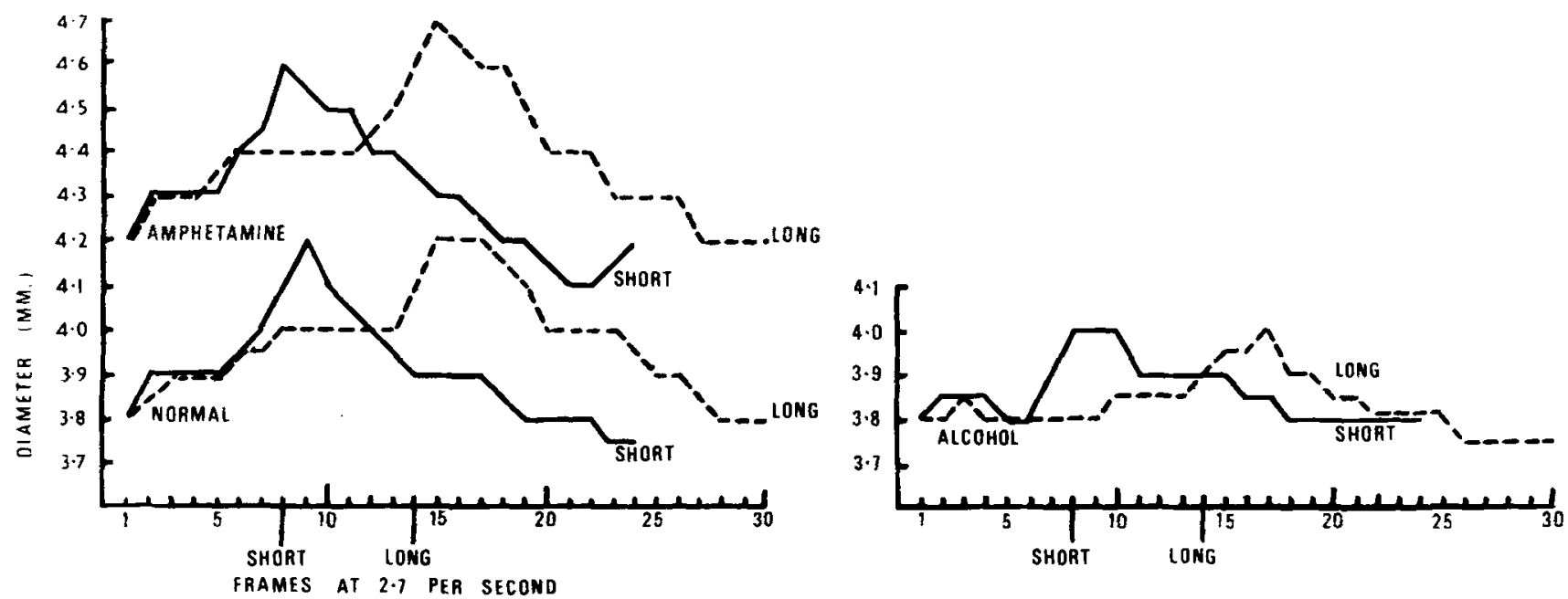

Fig. 1. Pupillary diameters in the three conditions, with long and short warning foreperiods. Cycles commence with the warning signal. The moments of occurrence of the response signal after a short or long delay are shown. 
Table I

Per Cent Increase in Pupillary Diameter, from Baseline to Response Peak, for the 3 Drug and 2 Warning Foreperiod Conditions

\begin{tabular}{|c|c|c|c|c|c|c|}
\hline \multirow[b]{2}{*}{ Subject } & \multicolumn{2}{|c|}{ Normal } & \multicolumn{2}{|c|}{ Alcohol } & \multicolumn{2}{|c|}{$\begin{array}{c}\text { Amphe- } \\
\text { tamine }\end{array}$} \\
\hline & Short & Long & Short & Long & Short & Long \\
\hline 1 & 11.9 & 14.3 & 7.7 & 2.6 & 10.0 & 10.0 \\
\hline 2 & 9.1 & 9.1 & 2.5 & 2.5 & 7.0 & 9.3 \\
\hline 3 & 10.0 & 10.0 & 5.3 & 5.3 & 11.1 & 16.6 \\
\hline 4 & 8.8 & 8.8 & 5.3 & 2.6 & 7.1 & 7.1 \\
\hline 5 & 13.9 & 18.6 & 7.9 & 10.5 & 14.0 & 16.3 \\
\hline 6 & 7.9 & 10.5 & 8.8 & 8.8 & 13.5 & 18.9 \\
\hline Mean & 10.3 & 11.9 & 6.3 & 5.4 & 10.5 & 13.0 \\
\hline
\end{tabular}

amphetamine were found to be significantly higher than those attained under the normal condition $(\mathrm{p}<.05$, $t=2.4, t$ test for correlated samples), while alcohol and normal did not differ significantly. When the per cent increase in pupillary diameters, from baseline to response peak, were calculated (see Table 1), the curves under alcohol were found to be flatter than were those under the normal condition $(\mathrm{p}<.001, \mathrm{t}=7.8)$, while normal and amphetamine did not differ significantly. In Table 2 can be seen the effects of the three drug conditions and the two foreperiod lengths upon reaction time. Both factors affected performance significantly $(F=7.01, \mathrm{df}=2 / 10, \mathrm{p}<.03$, and $F=6.85, \quad \mathrm{df}=1 / 5, \quad \mathrm{p}<.05$, respectively). Alcohol again accounted almost entirely for the drug effect, amphetamine and normal not differing significantly.

\section{DISCUSSION}

Amphetamine would appear to induce an increase in levels of baseline dilation without any effect upon RT, shape, or amplitude of the pupilary response peak. Its general effect is, in fact, comparable simply to a reduction in background intensities (Bradshaw, 1969). On the other hand, while alcohol was associated with the same average pupillary baselines as in the normal condition, nevertheless, the peak effects were flattened and the RT slowed. The absence of simple motor improvement under amphetamine is not a new finding (Costello, 1964). Nevertheless, the $11 \%$ average increase in pupillary baselines is not obviously associated with any other manifestations of a "tightening of the spring balance" (Kahneman et al, 1967). If it is assumed that in this task Ss were optimally aroused and motivated without amphetamine, then the most likely effect of this drug would be a small increase in baseline dilations. Conversely, the depressant effect of alcohol is manifested in the drop in motor performance and a change in peak effects. It is perhaps curious that there is not also a corresponding drop in baselines.
The decrease in RT in the long foreperiod trials has been reported earlier (Bradshaw, 1969). In the latter study, it was suggested that uncertainty as to time of arrival of the response signal was correspondingly reduced, if the signal had not already occurred.

\section{REFERENCES}

BRADSHAW, J. L. Load and pupillary changes in continuous processing tasks. British Journal of Psychology, 1968, 59, 265-271.

BRADSHAW, J. L. Background light intensity and the pupillary response in a reaction time task. Psychonomic Science, 1969, 14 271-272.

COLE, S. O. Experimental effects of amphetamine. Psychological Bulletin, 1967, $68,81-90$.

COSTELLO, C. G. The effects of depressant and stimulant drugs upon relationships between reaction time and stimulus light intensity. British Journal of Social \& Clinical Psychology, 1964, 3, 1-5.

KAHNEMAN, D., BEATTY, J., \& POLLACK, I.
Table 2

Mean Reaction-Times Obtained Under the Three Conditions, to Nearest $5 \mathrm{Msec}$

\begin{tabular}{|c|c|c|c|c|c|c|}
\hline \multirow[b]{2}{*}{ Subject } & \multicolumn{2}{|c|}{ Normal } & \multicolumn{2}{|c|}{ Alcohol } & \multicolumn{2}{|c|}{$\begin{array}{l}\text { Amphe- } \\
\text { tamine }\end{array}$} \\
\hline & Short & Long & Short & Long & Short & Long \\
\hline $\begin{array}{l}1 \\
2 \\
3 \\
4 \\
5 \\
6\end{array}$ & $\begin{array}{l}170 \\
200 \\
210 \\
180 \\
190 \\
200\end{array}$ & $\begin{array}{l}170 \\
185 \\
220 \\
165 \\
180 \\
190\end{array}$ & $\begin{array}{l}220 \\
360 \\
295 \\
200 \\
180 \\
280\end{array}$ & $\begin{array}{l}215 \\
350 \\
300 \\
180 \\
170 \\
245\end{array}$ & $\begin{array}{l}170 \\
200 \\
240 \\
155 \\
175 \\
200\end{array}$ & $\begin{array}{l}160 \\
190 \\
240 \\
150 \\
170 \\
190\end{array}$ \\
\hline Mean & 190 & 185 & 255 & 240 & 190 & 180 \\
\hline
\end{tabular}

Perceptual deficit during a mental task. Science, 1967, 157, 218-219.

WILKINSON, R. T, \& COLQUHOUN, W. P. Interaction of alcohol with incentive and with sleep deprivation. Journal of Experimental Psychology, 1968, 76, 623-629.

\section{NOTE}

1. This study was completed while the author was at the University of Otago, Dunedin, New Zealand.

\section{Processing of spatial location and figural identity in a simulated reading task ${ }^{1}$}

\author{
RICHARD L. TAYLOR, V. A. Hospital, \\ Syracuse, N.Y. 13210
}

A property of visual search is that different inputs come from different spatial locations. Figural and spatial information, that is, normally are correlated. Ss may normally (1) presenve the input in a correlated state (image theory), (2)decorrelate the input by selectively attending only to figures (abstraction), or (3) map the input into an orthogonal representation (paradoxical visual searchl. To evaluate these possibilities, $S s$ made cue-stimulus associations in a YES-NO RT task: Ss in Experiments 1 and 2 were trained on compound figure-location stimuli and then were tested either for locations alone or for figures alone, with the irrelevant variable being orthogonal; Ss in Experiment 3 were trained on locations and figures separately and then tested in a correlated condition.

\section{The results pointed to a model} incorporating aspects of (2) and (3).

One characteristic of searching a static visual display for a target and of processing a glimpse from a page of text is that different inputs come from different spatial locations. That is, stimulus location and figural information normally are correlated. For this reason, it is often difficult to know when reading and visual-search performance reflects the processing of spatial, figural, or combined spatial and figural uncertainty. Previous work has demonstrated that Ss will tend to process one of two letters before the other, when both appear simultaneously, if one occurs at a predictable location while the other appears at either one of two difference places (Taylor, 1968). This implies not only that spatial uncertainty is important in attention, but also that Ss may be able to process locations and 